\title{
Study on Chip Breakability Index During Longitudinal Turning of Cast and DMLS Additively Manufactured AISi10Mg Aluminum Alloy
}

\author{
Grzegorz Struzikiewicz' ${ }^{1 *}$, Bogdan Słodki², Wojciech Zębala², Emilia Franczyk ${ }^{2}$ \\ 1 Faculty of Machanical Engineering and Robotics, AGH University of Science and Technology, al. Mickiewicza \\ 30, 30-059 Cracow, Poland \\ 2 Faculty of Mechanical Engineering, Chair of Production Engineering, Cracow University of Technology, Al. \\ Jana Pawła II 37, 31-864, Cracow, Poland \\ * Corresponding author's e-mail: grzegorz.struzikiewicz@pk.edu.pl
}

\begin{abstract}
The article presents selected issues related to the process of turning samples made of the AlSi10Mg alloy with the use of various manufacturing technologies, i.e. casting and DMLS (Direct Metal Laser Sintering). Machining processes of cylindrical surfaces of samples made with these two methods were subjected to a comparative analysis. The main idea behind the research was to develop guidelines for turning parts obtained using laser powder sintering. Study on the influence of cutting parameters on the value of breakability index $C_{i n}$. as well as the type, shape and form of chips produced during longitudinal turning is presented. The chips were also measured and the results of the microscopic analysis of the chips form are described. Results showed that the values of $C_{i n}$ index for turning of the cast AlSi10MG alloy depend mainly on the value of feed $f$. According to adopted chip classification for the feed value of $f>0.1 \mathrm{~mm} / \mathrm{rev}$ the chips had a favorable, short form. In the case of turning the sample obtained by the DMLS method, the values of the chip breakability index $C_{i n}$ are not significantly dependent on the adopted ranges of cutting parameters. The Taguchi method was used to develop the conclusions obtained on the basis of the research results.
\end{abstract}

Keywords: machining, turning, AlSi10Mg aluminum alloy, additive manufacturing, DMLS, chip breakability.

\section{INTRODUCTION}

Just after steel, aluminum alloys are the second most used construction material. Due to their specific properties, i.e. density, corrosion resistance, good strength and stiffness, they are used, for example, in the automotive, aviation, machinery, manufacturing and transport industries $[1,2]$. One of the most common aluminum alloys is AlSi10Mg [3]. In addition to the properties already mentioned, it is characterized by a relatively low density and good thermal and electrical conductivity [3, 4]. In general, aluminum alloys have good machinability, mainly depending on the silicon content. A common problem, however, is their tendency to form built-up edges and low breakability of the chip, which is often continuous and with high strength $[5,6]$.
Increasing demands on machine parts quality make conventional manufacturing methods insufficient. In order to produce parts with complex, spatial geometry and relatively small dimensions, additive manufacturing (AM) technologies are more and more often used. These techniques use 3D CAD models, on the basis of which objects are manufactured by overlapping successive, thin layers of material $[1,7,8]$. One of the most common additive methods today is DMLS (Direct Metal Laser Sintering), which is an alternative to the casting process. It consists in selective, laser sintering of successive layers of metal powder. The main advantages of this technology include relatively high dimensional and shape accuracy, good repeatability and relatively high strength of the manufactured elements as well as almost no limitations in designing the geometry of the object. In terms of surface roughness, sintered parts 
are near as good as castings [9]. Besides aluminum alloys, various kinds of steels (e.g. 316L, 17$4 \mathrm{PH}$ ) and special alloys (e.g.Ti6A14V) are used to produce parts using DMLS [10, 11, 12].

Obviously, the capabilities of AM technology are somewhat limited. In practice, additional machining operations are often used to improve the dimensional and shape accuracy or better finish the surface of the product [13]. In the case of aluminum alloys, with some exceptions (e.g. alloys with high content of silicon), chemical composition does not significantly affect their machinability $[5,6,14]$. The effectiveness of further processing, however, depends on the structure of the workpiece material, which vary among elements made with different technologies. Research conducted by Read et al. [15] and Yan et al. [16] show that the structure of castings is more homogeneous, while objects made by sintering have a clearly layered, porous structure and material discontinuities resulting from incomplete remelting of the powder and the presence of oxide inclusions [1, 12, 16]. Segebade et al. [17] and Tang et al. [18] noticed strong anisotropic properties of AlSi10Mg sinters. Zyguła et al. [19] and Rosenthal et al. [20] showed that the structural defects of such objects can be eliminated by optimizing the parameters of the sintering process as well as the subsequent heat treatment. Franczyk et al. [21] concluded that in the case of EDM (Electrical Discharge Machining) treatment of the AlSi10Mg alloy, the method of sample preparation (casting/SLM (Selective Laser Melting)) influences the quality of the surface formed after cutting and the speed of the cutting process itself. In this case, more favorable results were obtained for samples made by SLM. A similar set of samples (AlSi10Mg, casting / DMLS) was used by Struzikiewicz et al. [22], who proved that in the case of orthogonal turning of laser sinters, products of lower surface finish are obtained. The problem was the appearance of burrs and chipping that adhered to the treated surface, reducing its quality. Zimmermann et al. [13], who conducted research on milling using analogous samples, came to very similar conclusions.

An inherent element of the cutting process is the phenomenon of chip formation, the type of which may have a significant impact on the process itself as well as on the quality of the manufactured product. As already mentioned, the disadvantageous properties of the chip make it difficult to cut aluminum alloys. Unfavorable shape and flow of the chip may cause damage to the machined surface [23]. Rubio et al. [23] showed that when turning aluminum alloys, shape of the chip depends on the cutting parameters: feed, cutting speed, depth of cut and interactions between them. It is also influenced by the structure of the material resulting from its production technology. Research done by Segebade et al. [17] revealed a strong influence of the AlSi10Mg sinter anisotropy on the shape and segmentation process of the chip during turning. Controlling and more efficient removal of chip from the cutting zone are possible thanks to the use of additional cooling [5]. Comparing the cast and sintered AlSi10Mg samples in the milling process, Zimmermann et al. [13] obtained discontinuous and spiral segment chips, respectively.

Hybrid machining, which combines the advantages of additive and subtractive manufacturing is currently one of the leading directions in the development of production processes. In this sense, the part is produced by additive methods and then machined, thus obtaining the required accuracy and surface quality. Therefore, there is a need to determine the machinability of materials obtained by AM methods and to analyze the impact of cutting parameters (feed, cutting speed and depth of cut) on the broadly understood quality of the machining process.

The authors made an attempt to determine the influence of the cutting parameters on the chip form. The tests were carried out for sintered and cast AlSi10Mg samples. The range of adopted parameters corresponded to the finishing process. As a result of the study, the values of the chip breakability index were determined and microscopic measurements of the chip surface were made.

\section{EXPERIMENTAL SETUP}

The aim of the experimental tests carried out was a comparative analysis of the chip form obtained as a result of longitudinal turning of parts made using two different methods, i.e. DLMS and casting. The processed material was AlSi10Mg aluminum alloy. Two parts with a circular crosssection were used in the research. This was a shaft with diameter $\phi=55 \mathrm{~mm}$ and length $L=140 \mathrm{~mm}$. The first one was made using the DMLS method by means of Renishaw AM 250 machine with AlSi10Mg metal powder and following parameters: laser power $-400 \mathrm{~W}$, diameter of the laser beam 
Table 1. Properties of the AlSi10Mg powder and mechanical properties of additively manufactured components [24]

\begin{tabular}{|l|c|}
\hline \multicolumn{2}{|c|}{ Technical data } \\
\hline Recommended minimum layer thickness & $25 \mu \mathrm{m}$ \\
\hline Accuracy for small items & $+/-20-50 \mu \mathrm{m}$ \\
\hline Accuracy for large items & $+/-0.2 \%$ \\
\hline Density & $2.7 \mathrm{~g} / \mathrm{cm}^{3}$ \\
\hline \multicolumn{2}{|c|}{ Mechanical properties at $20^{\circ} \mathrm{C}$} \\
\hline Tensile strength - horizontal direction (XY) & $442+/-6 \mathrm{MPa}$ \\
\hline Tensile strength - vertical direction (Z) & $417+/-27 \mathrm{MPa}$ \\
\hline Yield strength - horizontal direction (XY) & $264+/-2 \mathrm{MPa}$ \\
\hline Yield strength - vertical direction (Z) & $206+/-6 \mathrm{MPa}$ \\
\hline $\begin{array}{l}\text { Hardness (Vickers) - horizontal } \\
\text { direction (XY) }\end{array}$ & $216 \mathrm{HV} 0.5+/-5$ \\
\hline Hardness (Vickers) - vertical direction (Z) & $123 \mathrm{HV} 0.5+/-2$ \\
\hline
\end{tabular}

Table 2. Mechanical properties of the AlSi10Mg casting [22]

\begin{tabular}{|c|c|c|c|c|}
\hline Alloy & $R m \mathrm{MPa}$ & $A_{5} \%$ & $H B$ & Density $\mathrm{g} / \mathrm{cm}^{3}$ \\
\hline AlSi10Mg & 193 & 2.5 & 68 & 2.65 \\
\hline
\end{tabular}

$-70 \mu \mathrm{m}$, powder producer - Renishaw, particle size - 20-45 $\mu \mathrm{m}$, shape - spherical. AlSi10Mg alloy comprises aluminum alloyed with silicon of mass fraction up to $10 \%$, small quantities of magnesium and iron, along with other minor elements. The properties of powder and mechanical properties of additively manufactured components are presented in Table 1. The other part was cast shaft. Mechanical properties and the chemical composition of the cast material are presented in Tables 2 and 3, respectively. This alloy is used for complexshaped, high-strength, heavily and medium-loaded castings, such as gearbox housings, steering gear bodies and engine blocks in motor vehicles.

Microscopic analysis of the chips form was performed using a Bresser workshop microscope and a Keyence 3D microscope.

Design of the experiment was developed according to the Taguchi method. The influence of variable cutting parameters on the chip breakability index $C_{\text {in }}$ was analyzed.

Chip breakability index $C_{\text {in }}$ (Pusavec at al. [25]) is evaluated in the range from 0 to 1 according to the relationship described by formula 1. The longitudinal dimension of the chips was adopted as the main criterion when assessing the form of chips. For the chip length $L_{c h}$ a simplified classification has been adopted [26]:

- $L_{c h} \leq 25 \mathrm{~mm}$ - short chips, correct $\left(0<C_{i n}<0.5\right)$;

- $L_{c h}>25 \mathrm{~mm}$ and $L_{c h} \leq 50 \mathrm{~mm}$ - fair, acceptable chips $\left(0.5<C_{\text {in }}<1.0\right)$. Acceptable chip form is is their medial form possible to obtain in the machining process;

- $L_{c h}>50 \mathrm{~mm}$ - long, unfavorable chips $\left(C_{i n}=\right.$ const. $=1.0)$.

Lower $C_{i n}$ values represent better chip breakability as shown in Figure 1 [26].

$$
C_{\text {in }}\left(L_{c h}\right)=\left\{\begin{array}{c}
0.02 \cdot L_{c h} \text { if } 0 \leq L_{c h} \leq 50 \\
1 \text { if } L_{c h}>50
\end{array}\right.
$$

For the purposes of the statistical analysis of the research results, a matching function

Table 3. Chemical composition of AlSi10Mg alloy (\%) [22]

\begin{tabular}{|c|c|c|c|c|c|c|c|c|c|c|}
\hline $\mathrm{Si}$ & $\mathrm{Fe}$ & $\mathrm{Cu}$ & $\mathrm{Mn}$ & $\mathrm{Mg}$ & $\mathrm{Cr}$ & $\mathrm{Ni}$ & $\mathrm{Zn}$ & $\mathrm{Ti}$ & $\mathrm{Be}$ & $\mathrm{Ca}$ \\
\hline 9.738 & 0.312 & 0.011 & 0.436 & 0.202 & 0.0043 & $<0.0020$ & 0.0096 & 0.0041 & $<0.0003$ & 0.006 \\
\hline $\mathrm{Cd}$ & $\mathrm{Co}$ & $\mathrm{Ga}$ & $\mathrm{Na}$ & $\mathrm{Pb}$ & $\mathrm{Sn}$ & $\mathrm{Sr}$ & $\mathrm{V}$ & $\mathrm{Zr}$ & $\mathrm{Al}$ & - \\
\hline$<0.0005$ & $<0.001$ & $<0.002$ & 0.001 & $<0.005$ & $<0.005$ & $<0.001$ & $<0.002$ & $<0.002$ & 89.26 & - \\
\hline
\end{tabular}

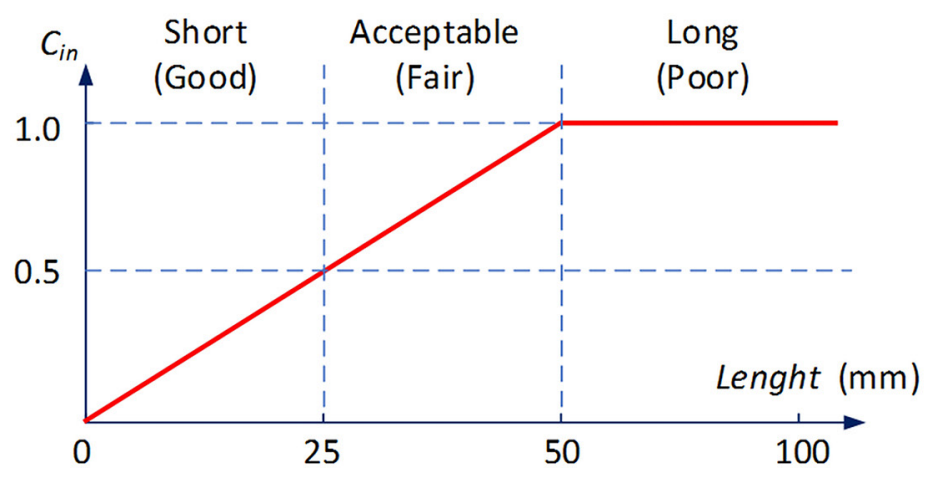

$[\mathbf{G}$

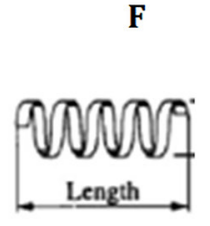

Fig. 1. Simplified classification of chip geometry (due to the length of chip (Lch)) [26] 
model was adopted according to the following formula (2):

$$
Y_{1}=y-\varepsilon=b_{0} x_{0}+b_{1} x_{1}+b_{2} x_{2}+b_{3} x_{3}
$$

where: $Y_{1}$ is the estimated response based on first order equation, and $\mathrm{y}$ is the measured parameter (e.g. surface roughness) on a logarithmic scale, $x_{0}=1$ (dummy variable), $x_{1}-x_{3}$ are logarithmic transformations of cutting speed, feed rate and depth of cut respectively, $\varepsilon$ is the experimental error and ' $b$ ' values are the estimates of corresponding parameters.

"The lower the better" analysis method of the $\mathrm{S} / \mathrm{N}$ ratio, represented by the formula (3) below, was chosen.

$$
S / N=-10 \cdot \log \left(\frac{1}{n} \sum_{i=1}^{n} y_{i}^{2}\right)
$$

The ranges of cutting parameters used in the tests are shown in Table 4. They have been selected so that they fit within the range recommended by the tool manufacturer. A cutting DCGT 11T304AS, IC20 grade made by ISCAR, was used for the tests. The cutting tool is shown in Figure 2.

Exemplary photographs of the chips obtained during the experiment as well as the values of chip breakability index $C_{i n}$ for turning both sintered and cast aluminum alloys are presented in Table 5.

\section{RESULTS AND DISCUSSION}

Summary of the results obtained for the adopted research plan is presented in Table 6. Mean values of chip breakability index $C_{i n}$ and the values of $\mathrm{S} / \mathrm{N}$ (signal to noise) ratio are given. The parameter values used in the 8th experiment turned out to be optimal for turning a cast sample. When turning the DMLS sample, all trials brought a favorable or acceptable form of chips.

Figure 3 presents a graphical presentation of the influence of variable factors on the values of chip breakability index $C_{\text {in }}$ for two types of processed materials.
The analysis of the results showed an insignificant effect of the cutting parameters on the values of chip breakability index when turning the laser sintered material. In this case, the chips obtained were in a short, favorable or acceptable form, most often arched. For the machining of cast material, the factor significantly influencing the values of chip breakability index was the feed $f$. Cutting speed $v_{c}$ and depth of cut $a_{p}$ had no significant effect on the chip form. Similar conclusions were reached by Zagórski et al. [14] and Rubio et al. [23], who analyzed the effect of cutting parameters on the quality of the machined surface after turning aluminum alloys. On the other hand Karolczak et al. [27] found, that the material of the cutting insert does not significantly effect on the chips form. The increase in the feed value had a positive effect on the chip breaking process. For feed values greater than $0.1 \mathrm{~mm} / \mathrm{rev}$, the chips had a short, correct form. The influence of the feed on the chip breakability index is shown in Figure 4. However, it should be noted that on the value of chip breakability index could be influenced by the method of cooling the cutting zone, as demonstrated by Svobodová et al. [5].

Properties of the material obtained in the process of remelting aluminum alloy granules in the laser sintering process are the most likely cause of differences in the form of chips. The distribution, thickness and number of layers in the DLMS process determine the mechanical properties of the manufactured object. Such materials also have
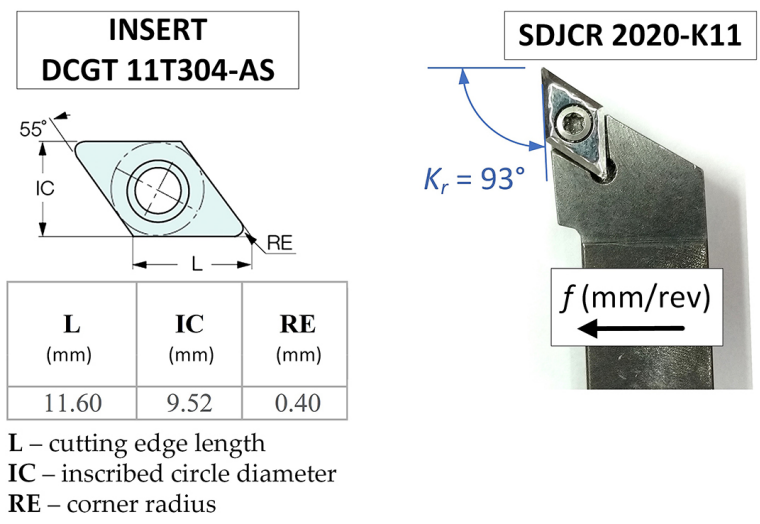

Fig. 2. The cutting tool

\begin{tabular}{|c|c|c|c|c|c|c|}
\hline No. & Coded parameter & Real parameter & \multicolumn{4}{|c|}{ Value } \\
\hline 1 & A & $\mathrm{f}(\mathrm{mm} / \mathrm{rev})$ & 0.038 & 0.077 & 0.115 & 0.153 \\
\hline 2 & B & $v_{c}(m / m i n)$ & \multicolumn{2}{|c|}{200} & \multicolumn{2}{|c|}{300} \\
\hline 3 & C & $a_{p}(m m)$ & \multicolumn{2}{|c|}{0.5} & \multicolumn{2}{|c|}{1.0} \\
\hline
\end{tabular}

Table 4. Values of variable parameters in the research plan 
Table 5. Summary of photographs and the values of chip breakability index $C_{i n}$ for laser sintered and cast material

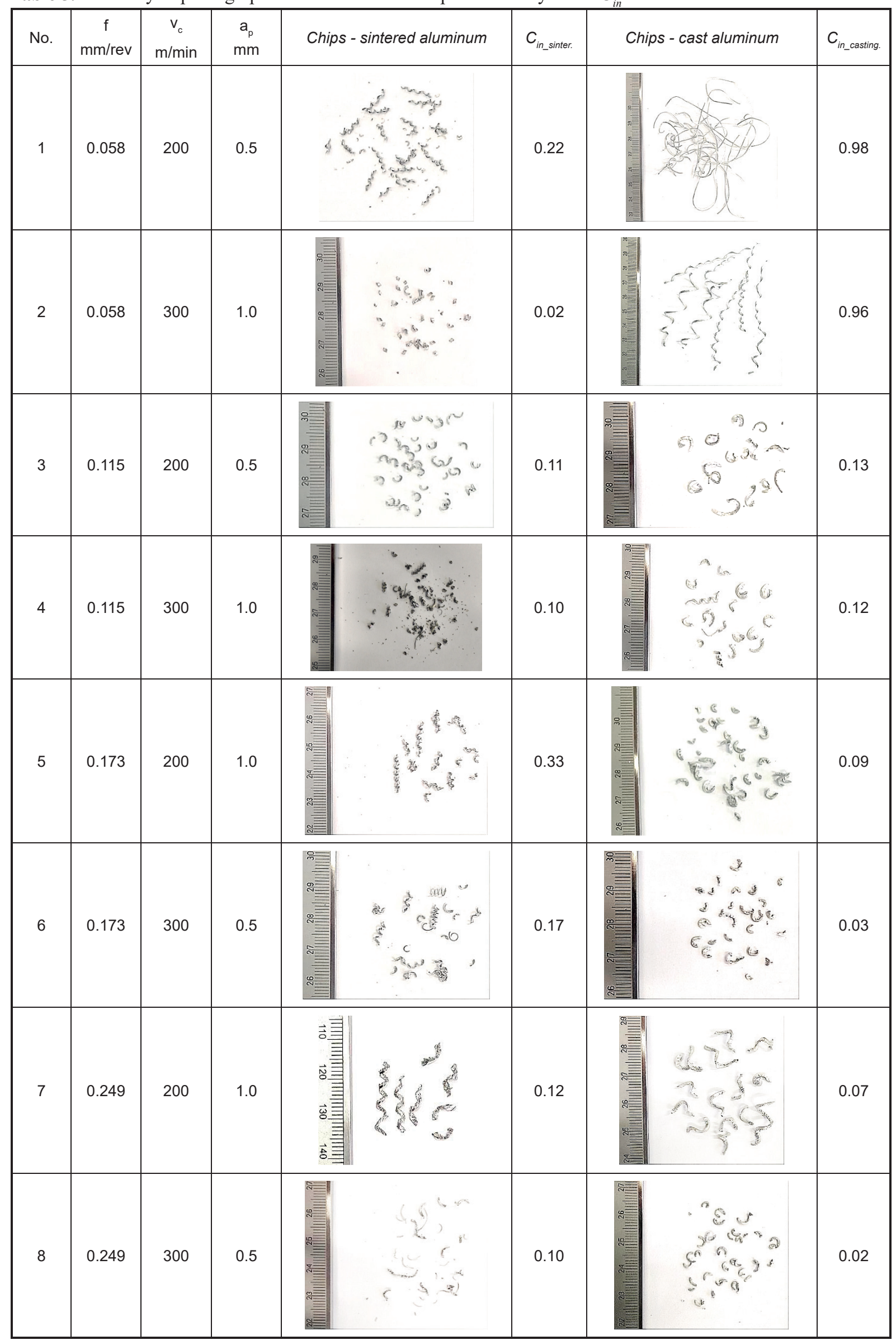


Table 6. Summary of the results - analysis of the Taguchi test plan

\begin{tabular}{|c|c|c|c|c|c|c|c|}
\hline $\mathrm{Nr}$ & $\begin{array}{c}f \\
(\mathrm{~mm} / \mathrm{rev})\end{array}$ & $\begin{array}{c}v_{c} \\
(\mathrm{~m} / \mathrm{min})\end{array}$ & $\begin{array}{c}a_{p} \\
(\mathrm{~mm})\end{array}$ & $\begin{array}{c}C_{\text {in_mean }} \\
(\text { sinter })\end{array}$ & $\begin{array}{c}S / N \\
(\text { sinter })\end{array}$ & $\begin{array}{c}C_{\text {in_mean }} \\
\text { (casting) }\end{array}$ & $\begin{array}{c}S / N \\
\text { (casting) }\end{array}$ \\
\hline 1 & 0.058 & 200 & 0.5 & 0.22 & 13.13 & 0.98 & 0.14 \\
\hline 2 & 0.058 & 300 & 1.0 & 0.02 & 33.96 & 0.96 & 0.32 \\
\hline 3 & 0.115 & 200 & 0.5 & 0.11 & 19.15 & 0.13 & 17.87 \\
\hline 4 & 0.115 & 300 & 1.0 & 0.10 & 19.98 & 0.12 & 18.56 \\
\hline 5 & 0.173 & 200 & 1.0 & 0.33 & 9.61 & 0.09 & 21.06 \\
\hline 6 & 0.173 & 300 & 0.5 & 0.17 & 15.37 & 0.03 & 30.60 \\
\hline 7 & 0.249 & 200 & 1.0 & 0.12 & 18.40 & 0.07 & 23.24 \\
\hline 8 & 0.249 & 300 & 0.5 & 0.10 & 19.98 & 0.02 & 32.19 \\
\hline
\end{tabular}

Effect of variable factors on the mean $C_{\text {in }}$ value - DMLS sample

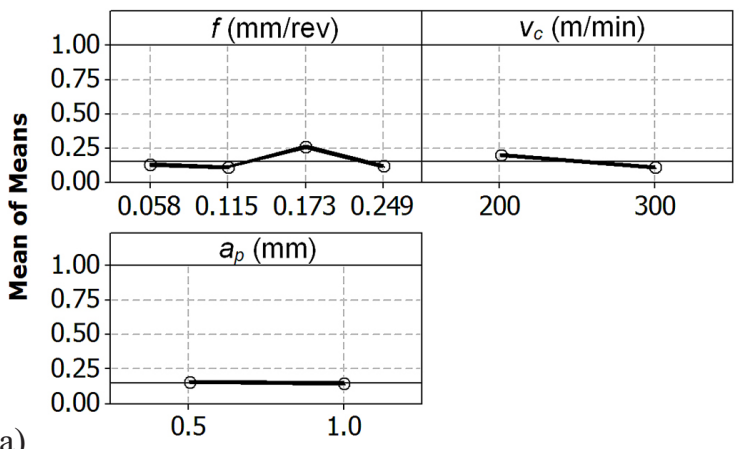

Effect of variable factors on the mean $C_{i n}$ value - cast sample

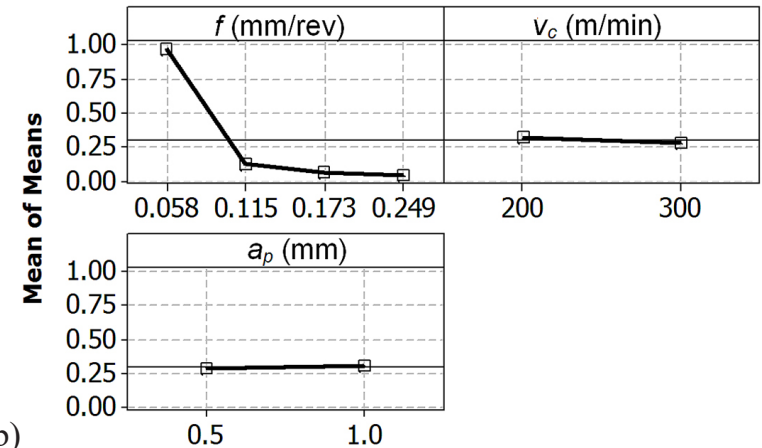

Fig. 3. Effect of test variables on the values of $C_{i n}$. Turning of (a) laser sintered aluminum (b) cast aluminum

$C_{\text {in }}$ as a function of feed $f$ - DMLS sample

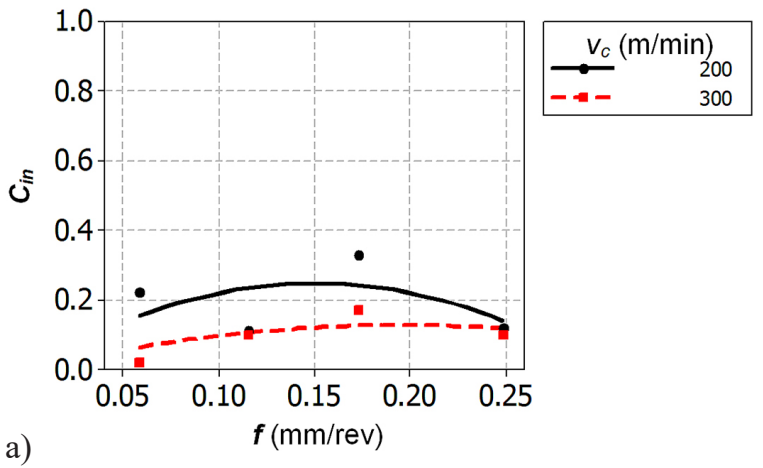

$C_{\text {in }}$ as a function of feed $f$ - cast sample

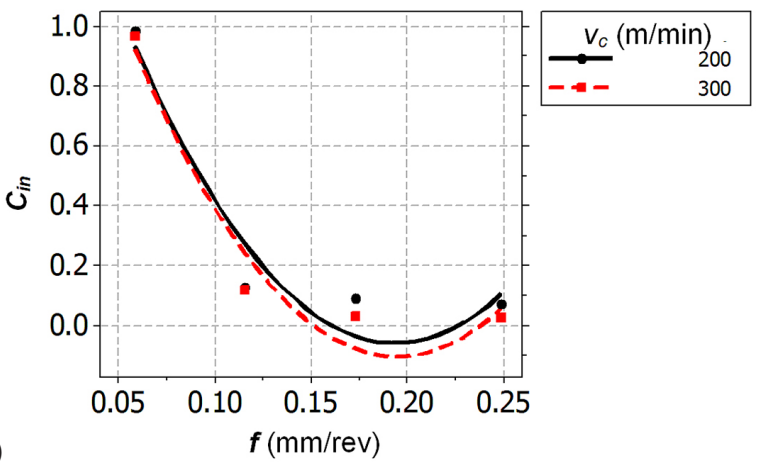

Fig. 4. $C_{\text {in }}$ as a function of feed $f$. Turning of (a) laser sintered aluminum (b) cast aluminum

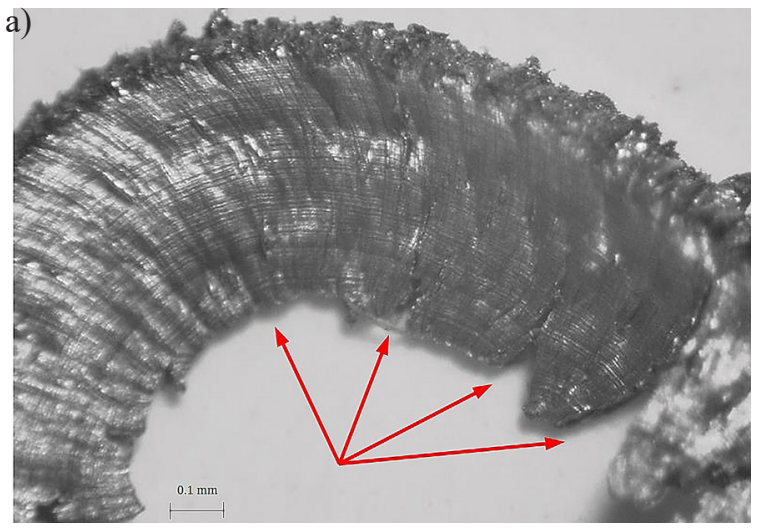

b)

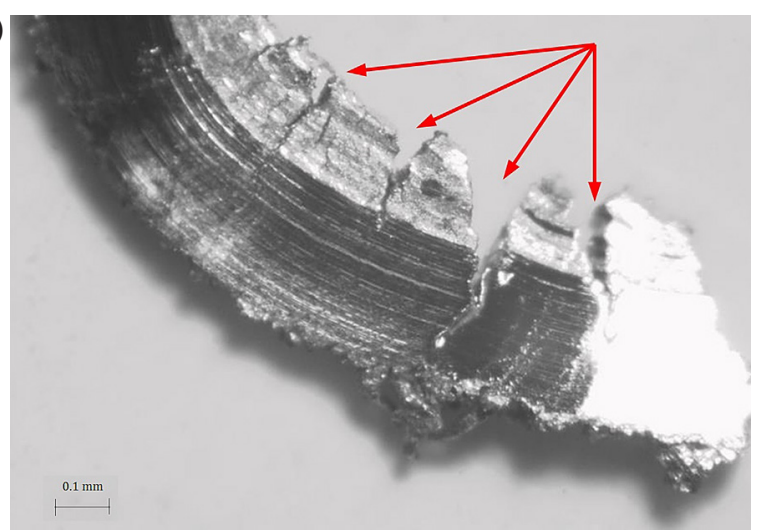

Fig. 5. Cracks on the inner (a) and outer (b) surface of the chip - turning of sintered material 
greater porosity in relation to castings. This can be the reason that accelerates the process of microcracking during the formation of the chip, resulting in its faster breaking. Development of cracks can also be enhanced by curling as the chips are formed. The most common form of chips obtained in the research is short, arched and loose. Examples of microscopic images of chips with marked cracks are presented in Figure 5. The observation of the chip surface also revealed numerous deformations and sticked particles of the sintered material. The cause of their presence is the phenomenon of tearing of the processed material particles from the machined surface by the cutting tool and then their adherence to the chip. There are areas with weaker bonding of material particles and pores in a workpiece made by DMLS. It was described in detail by Struzikiewicz at al. [9].

\section{CONCLUSIONS}

Following conclusions can be made on the basis of the obtained results and the analyzes carried out to determine the value of the chip breakability index in longitudinal turning (for selected cutting tool) of the DMLS sintered and cast AlSi10Mg aluminum alloy samples:

- The values of $C_{\text {in }}$ index for turning of the cast AlSi10Mg alloy depend mainly on the value of feed $f$. This is in line with the general state of the art in the processing of aluminum alloys. According to adopted chip classification and analysis of their form, it is stated that for the feed value of $f>0.1 \mathrm{~mm} / \mathrm{rev}$, the chips had a favorable, short form.

- In the case of turning the AlSi10Mg sample obtained by the DMLS method, the values of the chip breakability index are not significantly dependent on the adopted ranges of cutting parameters, i.e. feed $f$, depth of cut $a_{p}$ and cutting speed $v_{c}$. Chips characterized by a short, favorable or acceptable form, most often arched, were observed. In addition, microscopic observation of the chip surface revealed numerous microcracks as well as discontinuities and deformations of the material, which presence supports the chip breaking process. Numerous stickings of processed material particles on the chip surface were also observed, which indicates weaker bonding of particles in this type of material.
The research was carried out using cutting tool with selected geometry. Presented conclusions and recommendations relate to the tested tool only. Methods of additive manufacturing of machine parts based on the use of metal powders are still innovative technologies. Machining of materials obtained by the DMLS method is not fully understood and will be the subject of further research.

\section{Acknowledgements}

This work was financed from the funds of the Ministry of Education and Science by Agreement No. DNK/SP/513880/2021 of 22 December 2021, the project " $14^{\text {th }}$ School of Machining and the $43^{\text {rd }}$ Scientific School of Abrasive Machining", under the programme "Perfect Science".

\section{REFERENCES}

1. Olakanmi E.O., Cochrane R.F., Dalgarno K.W. A Review on Selective Laser Sintering/ Melting (SLS/SLM) of Aluminium Alloy Powders: Processing, Microstructure, and Properties. Progress in Materials Science. 2015; 74: 401-477.

2. Chen J., Hou W., Wang X., Chu S., Yang Z. Microstructure, Porosity and Mechanical Properties of Selective Laser Melted AlSi10Mg. Chinese Journal of Aeronautics. 2020; 33: 2043-2054.

3. Li Z., Nie Y., Liu B., Kuai Z., Zhao M., Liu F. Mechanical Properties of A1Si10Mg Lattice Structures Fabricated By Selective Laser Melting. Materials \& Design. 2020; 192: 108709.

4. Wanga L., Wanga S., Hong X. Pulsed SLM-manufactured AlSi10Mg Alloy: Mechanical Properties And Microstructural Effects of Designed Laser Energy Densities. Journal of Manufacturing Processes. 2018; 35: 492-499.

5. Svobodová J., Luňák M., Lukáč I. Identification of the "Snowflakes" on the Machined Surface of the AlSi10Mg Alloy Casting. Manufacturing Technology. 2019; 19: 868-873.

6. Santos M.C., Machado A.R., Sales W.F., Barrozo M.A.S., Ezugwu E.O. Machining of aluminum alloys: a review. The International Journal of Advanced Manufacturing Technology. 2016; 86: 3067-3080.

7. Kim M.S. Effects of Processing Parameters of Selective Laser Melting Process on Thermal Conductivity of AlSi10Mg Alloy. Materials. 2021; 14(9): 2410.

8. Radosh A., Kuczko W., Wichniarek R., Górski F. Prototyping of Cosmetic Prosthesis Of Upper Limb 
Using Additive Manufacturing Technologies. Advances in Science and Technology Research Journal. 2017; 11: 102-107.

9. Struzikiewicz G., Zębala W., Słodki B. Cutting Parameters Selection for Sintered Alloy AlSi10Mg Longitudinal Turning. Measurement. 2019; 138: 39-53.

10. Kim K.T. Mechanical Performance of Additively Manufactured Austenitic 316L Stainless Steel. Nuclear Engineering and Technology. DOI: 10.1016/j. net.2021.07.041.

11. Walczak M., Szala M. Effect of Shot Peening on The Surface Properties, Corrosion and Wear Performance of 17-4PH Steel Produced by DMLS Additive Manufacturing. Archives of Civil and Mechanical Engineering. 2021; 21(157): 5-20.

12. Żebrowski R., Walczak M. Effect of The Shot Peening on Surface Properties and Tribological Performance of Ti-6Al-4V Alloy Produced by Means of DMLS Technology. Archives of Metallurgy and Materials. 2019; 64(1): 377-386.

13. Zimmermann M., Müller D., Kirsch B., Greco S., Aurich J.C. Analysis of the Machinability When Milling AlSi10Mg Additively Manufactured Via Laser-Based Powder Bed Fusion. The International Journal of Advanced Manufacturing Technology. 2021; 112: 989-1005.

14. Zagórski I., Warda T. Effect of Technological Parameters on the Surface Roughness of Aluminium Alloys After Turning. Advances in Science and Technology Research Journal. 2018; 12: 144-149.

15. Read N., Wang W., Essa K., Attallah M.M. Selective Laser Melting of AlSi10Mg Alloy: Process Optimisation and Mechanical Properties Development. Materials and Design. 2015; 65: 417-424.

16. Yan Q., Song B., Shi Y. Comparative Study of Performance Comparison of AlSi10Mg Alloy Prepared by Selective Laser Melting and Casting. Journal of Materials Science \& Technology. 2020; 41: 199-208.

17. Segebade E., Gerstenmeyer M., Dietrich S., Zanger F. Schulze: Influence of Anisotropy of Additively Manufactured AlSi10Mg Parts on Chip Formation During Orthogonal Cutting. Procedia CIRP. 2019;
82: 113-118.

18. Tang M., Pistorius P.C. Anisotropic Mechanical Behavior of A1Si10Mg Parts Produced by Selective Laser Melting. The Minerals, Metals \& Materials Society. 2017; 69: 516-522.

19. Zyguła K., Nosek B., Pasiowiec H., Szysiak N. Mechanical Properties and Microstructure of AlSi10Mg Alloy Obtained by Casting and SLM Technique. World Scientific News. 2018; 104: 462-472.

20. Rosenthal I., Tiferet E., Ganor M., Stern A. Postprocessing of AM-SLM AlSil0Mg specimens: Mechanical properties and fracture behaviour. The Annals of "Dunarea de Jos" University of Galati: Fascicle XII, Welding Equipment and Technology. 2015; 26: 33-38.

21. Franczyk E., Machno M., Zębala W. Investigation and optimization of the SLM and WEDM processes. Parameters for the AlSi10Mg-sintered part. Materials. 2021; 14(2): 410.

22. Struzikiewicz G., Sioma A. Evaluation of surface roughness and defect formation after the machining of sintered aluminum alloy AlSi10Mg. Materials. 2020; 13(7): 1662.

23. Rubio E.M., Camacho A.M., Sánchez-Sola J.M., Marcos. M. Chip Arrangement in the dry cutting of aluminium alloys. Journal of Achievements in Materials and Manufacturing Engineering. 2006; 16(1-2): 164-170.

24. Renishaw https://www.renishaw.pl/pl/42225.aspx (access 11.07.2021).

25. Pusavec F., Deshpande A., Yang S., M’Saoubi R., Kopac J., Dillon Jr. O.W., Jawahir I.S. Sustainable machining of high temperature nickel alloy Inconel 718: Part 2. Chip breakability and optimization. Journal of Cleaner Production. 2015; 87: 941-952.

26. Zębala W., Struzikiewicz G., Słodki B. Reduction of power consumption by chip breakability control in Ti6Al4V titanium alloy turning. Materials. 2020; 13(11): 2642.

27. Karolczak P., Kołodziej M., Kowalski M. Effectiveness of diamond blades in the turning of aluminium composites. Advances in Science and Technology Research Journal. 2020; 14(4); 262-272. 